\title{
Evaluation of the altimetric information from RADARSAT-1, ASTER and SRTM data for topographic mapping in the Amazon Region
}

\author{
Waldir Renato Paradella and Cleber Gonzales de Oliveira \\ Earth Observation Coordination (OBT), Remote Sensing Division (DSR) \\ National Institute for Space Research (INPE) \\ São José dos Campos, Brazil \\ (waldir, cleber@ltid.inpe.br)
}

\begin{abstract}
Brazilian Amazon is a vast territory rich in natural renewable and non-renewable resources. Due to the adverse environmental condition (rain, cloud, dense vegetation, poor access), topographic information is still poor, and when available needs to be up-dated or re-mapped. In this paper, the feasibility of using altimetric information for topographic mapping through orbital stereoscopic (ASTER, RADARSAT-1) and interferometric (SRTM-3) DEMs (Digital Elevation Models) was investigated for two regions in the Brazilian Amazon: Tapajós National Forest (flat terrain) and Serra dos Carajás (mountainous relief). The quality of information produced from these data was evaluated regarding field altimetric measurements. Precise topographic field information acquired from Differential Global Positioning System (DGPS) was used as Ground Control Points (GCPs) for the modeling of the stereoscopic DEMs and as Independent Check Points (ICPs) for the calculation of altimetric accuracies of the products. The investigation has shown that the accuracy of the altimetric information derived from Fine RADARSAT-1, ASTER and SRTM-3 DEMs met the requirements for a semi-detailed (1:100,000-map) scale as requested by the Brazilian Standard for Cartographic Accuracy. Furthermore, SRTM-3 DEM was more accurate than stereoscopic DEMs. The additional great advantage of using SRTM-3 is the free access data. However, up-dated planimetric information is also necessary for cartographic production. Thus it is suggested a combination of altimetry derived for SRTM-3 and planimetry from high-resolution SAR (Fine RADARSAT-1, PALSAR) or if possible optical data (ASTER, SPOT) for topographic mapping at semi-detailed scale in similar environments of the Brazilian Amazon, where terrain information is seldom available or presents low quality.
\end{abstract}

Keywords- DEM, RADARSAT-1, ASTER, SRTM-3, Brazilian Amazon Region

\section{INTRODUCTION}

Brazilian Amazon, with almost 5,500,000 km², presents, under an apparently homogeneous forest physiognomy, an enormous spatial variability in climate, geology, soils, river systems, plant and animal communities. Due to the adverse environmental condition (rain, cloud, dense vegetation, poor access), the usage of optical data for regular basis coverage is expensive or even not possible. As a consequence, the Brazilian topography is still poorly known, with almost $25 \%$ of the area covered by maps at reconnaissance scale (1: 250,000 up to $1: 1,000,000)$. For the remainder of the region, the cartography at semi-detailed scale $(1: 100,000)$ needs to be updated or re-mapped [1].

DEM is a primary input for topographic mapping. With the advent of RADARSAT-1 in 1995, providing data with day or night, all-weather imaging capability and multiple modes (distinct look azimuth, incidence angle, spatial resolution and imaged area), DEMs could be for the first time systematic generated using orbital stereoscopy. The ASTER sensor, launched in 1999 on board of Terra platform, also allowed the generation of optical stereoscopic DEMS from the VNIR band 3 (nadir and backwards). Several results have been published in the literature with a general consensus of the elevation accuracy with RADARSAT-1: around $20 \mathrm{~m}$ for Standard and $12 \mathrm{~m}$ for Fine stereo-pairs [2]. With ASTER stereo-pairs elevation accuracy has been published ranging from $7 \mathrm{~m}$ to 18 $\mathrm{m}[3,4]$. The extrapolation of these results for operational use in the moist tropics should be taken with caution. Firstly, these investigations were concentrated in sites with favorable environmental (low to moderate vegetation cover, well defined ground features within the RS images, etc.) and experimental conditions (ancillary planialtimetric data with high quality and quantity to derive DEMs and test accuracies). Secondly, ground features are generally not available or poorly expressed in RS images for this environment, particularly in SAR. Thus, GCPs with quality, number and distribution is a critical point for the operational use of the technology in the tropics. These aspects have not been deeply addressed in the literature.

With the SRTM mission in February 2000, interferometric DEMs were also available for the globe. The vertical accuracy in the SRTM-3 (3 arc-seconds) is stated as $\pm 16 \mathrm{~m}$ with $90 \%$ confidence level. Results related to the use of SRTM-3 DEM in the tropics (Ecuador, Honduras, Colombia) indicated an average error of $8 \mathrm{~m}$ in elevation and an overall quality more accurate than available on 1: 50.000 scale cartographically derived air-photos DEM [5]. In the present research, the altimetric quality of DEMs generated from RADARSAT-1, ASTER and SRTM-3 data was evaluated for distinct terrains in the Brazilian Amazon. The investigation aimed to demonstrate how the altimetry derived from SAR and optical data can be applied to overcome the critical lack of topographic information in the Brazilian Amazon Region. 


\section{STUdy Sites}

Two distinct test-sites located in the central and the easternmost border of the Brazilian Amazon region were selected for the investigation: Tapajós National Forest and Serra dos Carajás, both in Pará State (Fig 1). The Tapajós National Forest is located at the lower Tapajós River region, within the Belterra municipality. It is characterized by low terrain (altitudes from 30 to 170 meters). Geologically, the area is within the Amazonas Sedimentary Basin, with fluvial to lacustrine sediments of the Alter do Chão Formation, part of the Javari Group, with Tertiary age. The vegetation is typical of the dense tropical forest showing high plateaus with emergent trees and uniform cover (Dense Ombrophilous Forests of Lowlands), and sections of low and dissected plateaus with few emergent and high density of palm trees (Open Ombrophilous Forests). Land use is related to subsistence agriculture, few cash crops and cattle raising. The site encompasses around $1940 \mathrm{~km}^{2}$ and comprises part of two 1:100,000 scale topographic sheets produced from black and white airphotos by Brazilian Army (DSG) during the 1973-1983 period.

The Carajás Province is the most important Brazilian mineral province with the world's largest iron deposits. The region is characterized by a set of hills and plateaus known as Serra dos Carajás (altitudes from 500 to 900 meters) surrounded by southern and northern lowlands (altitudes around 200 meters), totally covered by Ombrophilous Equatorial forest. Geologically the Province includes basement and volcano-sedimentary rocks of the Archean Itacaiunas Shear Belt and anorogenic granites with Proterozoic ages. The study area with around $3.736 \mathrm{~km}^{2}$ encompasses the Água Azul do Norte, Canaã dos Carajás, Marabá and Parauapebas municipalities. It comprises the Serra dos Carajás topographic sheet $(1: 100,000$ scale) produced from black and white airphotos by the Brazilian Institute of Geography and Statistics (IBGE) during the 1979-1981 period.

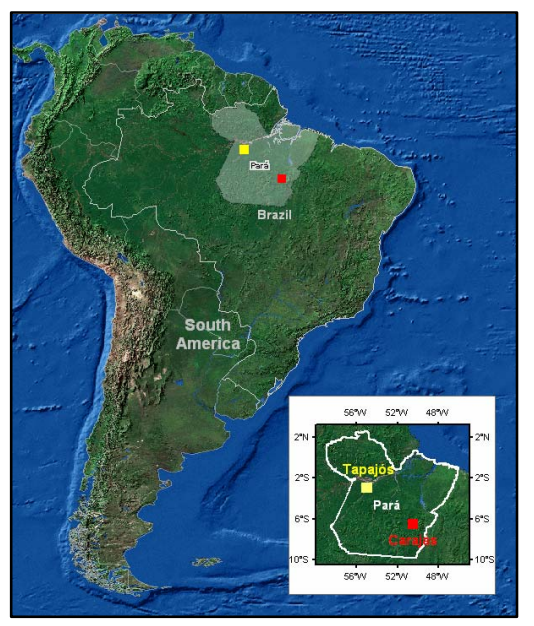

Fig. Location of the study areas in the Pará State.

III. DATA SET

The characteristics of the RADARSAT-1 and ASTER stereo-pairs are presented in Tables 1, 2, and 3.
TABLE 1. Fine RADARSAT-1 (Tapajós)

\begin{tabular}{|c|c|c|}
\hline Site & \multicolumn{2}{|c|}{ Tapajós National Forest } \\
\hline Beam & Fine 2 & Fine 5 \\
\hline Orbit & Descending & Descending \\
\hline Data & $20 / 09 / 2000$ & $27 / 09 / 2000$ \\
\hline Incidence & $39^{\circ}-42^{\circ}$ & $45^{\circ}-48^{\circ}$ \\
\hline Resolution & $8.7 \times 8.4 \mathrm{~m}$ & $7.8 \times 8.4 \mathrm{~m}$ \\
\hline Area & $43 \times 43 \mathrm{Km}$ & $43 \times 43 \mathrm{Km}$ \\
\hline Pixel & $6.25 \times 6.25 \mathrm{~m}$ & $6.25 \times 6.25 \mathrm{~m}$ \\
\hline Look & $1 \times 1$ & $1 \times 1$ \\
\hline Bits & 16 bits & 16 bits \\
\hline
\end{tabular}

TABLE 2. Fine RADARSAT-1 (Carajás)

\begin{tabular}{|c|c|c|c|c|}
\hline Site & \multicolumn{4}{|c|}{ Serra dos Carajás } \\
\hline Beam & Fine 2 & Fine 5 & Fine 2 & Fine 5 \\
\hline Orbit & Descend. & Descend. & Ascend. & Ascend. \\
\hline Data & $07 / 12 / 2001$ & $15 / 12 / 2001$ & $13 / 02 / 2002$ & $20 / 12 / 2001$ \\
\hline Incid. & $39^{\circ}-42^{\circ}$ & $45^{\circ}-48^{\circ}$ & $39^{\circ}-42^{\circ}$ & $45^{\circ}-48^{\circ}$ \\
\hline Resol. & $8.7 \times 8.4 \mathrm{~m}$ & $7.8 \times 8.4 \mathrm{~m}$ & $8.7 \times 8.4 \mathrm{~m}$ & $7.8 \times 8.4 \mathrm{~m}$ \\
\hline Area & $62 \times 56 \mathrm{Km}$ & $57 \times 50 \mathrm{Km}$ & $43 \times 43 \mathrm{Km}$ & $43 \times 43 \mathrm{Km}$ \\
\hline Pixel & $6.25 \times 6.25 \mathrm{~m}$ & $6.25 \times 6.25 \mathrm{~m}$ & $6.25 \times 6.25 \mathrm{~m}$ & $6.25 \times 6.25 \mathrm{~m}$ \\
\hline Look & $1 \times 1$ & $1 \times 1$ & $1 \times 1$ & $1 \times 1$ \\
\hline Bits & 16 bits & 16 bits & 16 bits & 16 bits \\
\hline
\end{tabular}

TABLE 3. Standard RADARSAT-ASTER (Carajás.)

\begin{tabular}{|c|c|c|c|}
\hline Site & \multicolumn{3}{|c|}{ Serra dos Carajás } \\
\hline Beam & Standard 5 & Standard 5 & $\begin{array}{c}\text { ASTER } \\
\text { VNIR 3 }\end{array}$ \\
\hline Orbit & Descend. & Descend. & - \\
\hline Data & $31 / 05 / 1996$ & $11 / 09 / 1996$ & $16 / 08 / 2001$ \\
\hline Incid. & $36^{\circ}-42^{\circ}$ & $45^{\circ}-49^{\circ}$ & - \\
\hline Resol. & $24.2 \times 27 \mathrm{~m}$ & $22.9 \times 27 \mathrm{~m}$ & $15 \mathrm{~m}$ \\
\hline Area & $100 \times 100 \mathrm{Km}$ & $100 \times 100 \mathrm{Km}$ & $60 \times 60 \mathrm{Km}$ \\
\hline Pixel & $12.5 \times 12.5 \mathrm{~m}$ & $12.5 \times 12.5 \mathrm{~m}$ & $15 \mathrm{~m}$ \\
\hline Look & $1 \times 4$ & $1 \times 4$ & - \\
\hline Bits & 16 bits & 16 bits & 8 bits \\
\hline
\end{tabular}

\section{METHODOLOGICAL APPROACH}

\section{A. DGPS Field Measurements}

Precise planialtimetric measurements from Differential Global Positioning System (DGPS) were acquired in the terrain, and used as Ground Control Points (GCPs) for the modeling of the DEMs and as Independent Check Points (ICPs) for the calculation of altimetric accuracies of the products. Two dual frequency geodesic receptors were used for the static DGPS measurements. A total of 47 static points was collected in Tapajós, and 50 points were acquired in Carajás. In addition around 35,000 kinematic measurements were collected for both areas. The dataset was corrected for ionospheric and tropospheric effects. The maximum errors

Identify applicable sponsor/s here. (sponsors) 
with a probability of $68.3 \%(1 \sigma)$ for the measurements in Tapajós were $6.52 \mathrm{~cm}$ (latitude), $19.66 \mathrm{~cm}$ (longitude) and $17.74 \mathrm{~cm}$ (geometric altitude). The maximum errors in Carajás were $18 \mathrm{~cm}$ (latitude), $75 \mathrm{~cm}$ (longitude) and $24 \mathrm{~cm}$ (geometric altitude). The geographical coordinates were related to the SAD 69 datum. For the transformation of geometric into ortometric altitudes, the MAPGEO98 model was used with absolute and relative accuracies of $1.5 \mathrm{~m}$ and $1.0 \mathrm{~cm} / \mathrm{Km}$, respectively.

\section{B. Generation of Stereoscopic DEMs}

Two kinds of stereoscopy were addressed in the research: (1) the across-track stereoscopic using two distinct orbits (RADARSAT-1), and (2) the along-track stereoscopy with scenes from the same orbit using fore and aft viewing (ASTER). For the first approach, two distinct models based on OrthoEngine software (PCI Geomatics) are available to compute the stereo model geometry and the 3D intersections for the DEMs generation: RADARSAT-1 Specific and HighResolution (Toutin's model). The first model takes advantage of the satellite positioning information, reducing the requirement for numerous well-distributed ground control points for the DEM generation while maintaining positional accuracy and high levels of detail. The model operates on a monoscopic basis, which considers each scene separately to form the model. The elevation is estimated by determining the solution, which satisfies the geometry, defined by the two (stereo) satellite positions, calculated slant ranges and Doppler planes. The addition of GCPs refines the model and improves its accuracy. The second alternative (High-Resolution) is based on geometric and stereoscopic models equivalent to the colinearity and co-planarity equations in photogrammetry, which reflect the physical reality of the complete viewing geometry taking into account the distortions of platform, sensor, Earth, projection. Once the geometric model is computed, quasiepipolar curve images are generated and the elevation parallax is derived based on automated image matching procedure, which utilizes a multiscale area correlation with a mean normalized cross-correlation approach [6].

\section{SRTM DEMS}

SRTM data are available in 3-arc seconds in HGT file format, covering $1^{\circ} \times 1^{\circ}$ on the ground. The data were acquired at $\mathrm{ftp} / / \mathrm{e} 0$ srp01u.ecs.nasa.gov/srtm/version2/SRTM3 in Lat/Long coordinates with the WGS84 horizontal datum and the EGM96 vertical datum. The data were imported and the HGT files were merged into continuous DEM (PCI format), followed by the application of an interpolation function to fill no-data holes based on Geomatica Focus software (PCI Geomatics).

\section{RESULTS}

The DEMs for Tapajós and Carajás are presented in Figures $2,3,4,5$ and 6 .

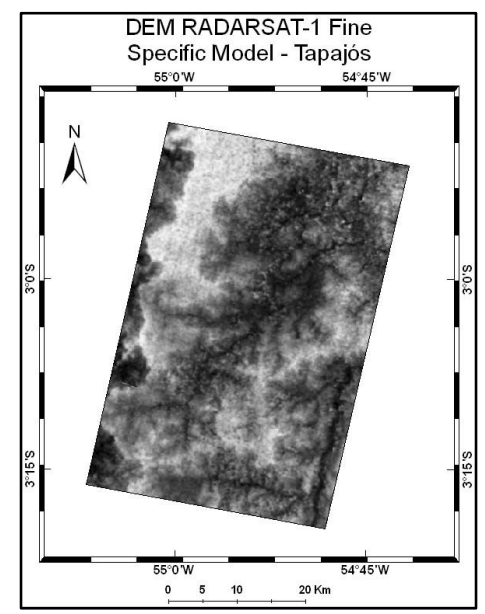

Fig. 2. RADARSAT-1 F2/F5 DEM (descend.) for Tapajós.

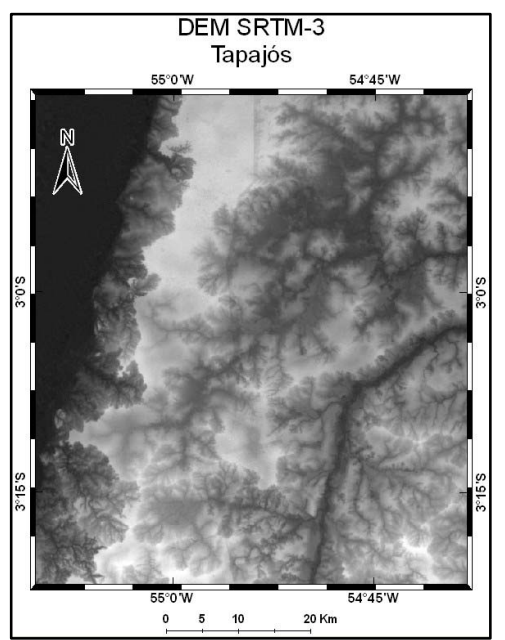

Fig. 3. SRTM-3 DEM for Tapajós.

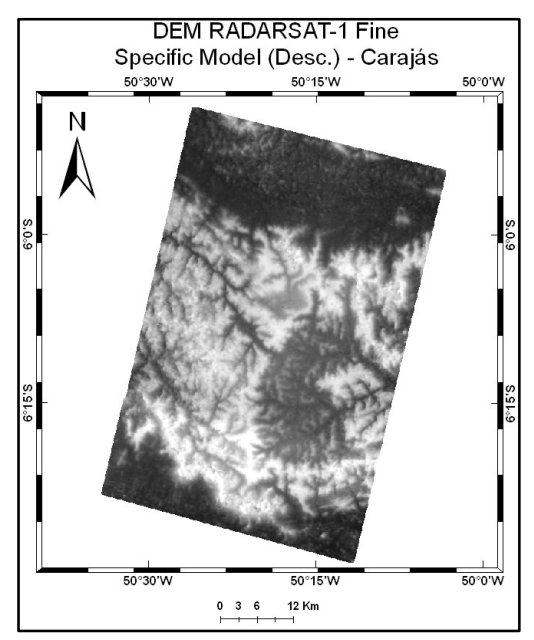

Fig. 4. RADARSAT-1 F2/F5 DEM (descend.) for Carajás. 


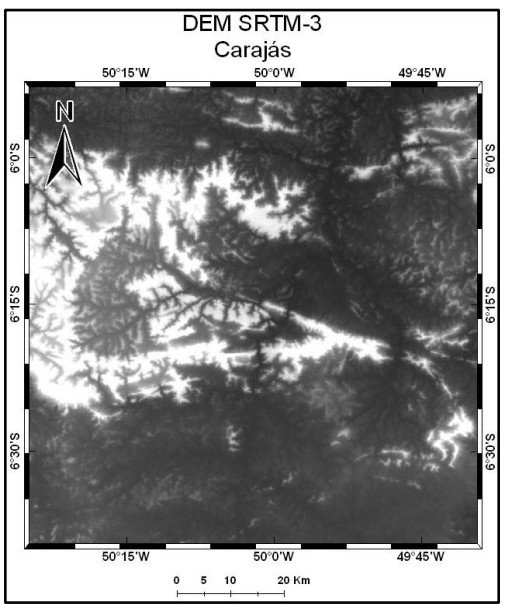

Fig. 5. DEM SRTM-3 for Carajás.

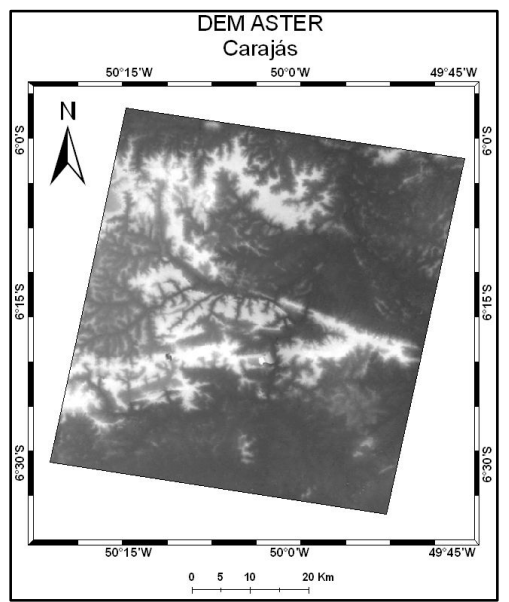

Fig. 6. ASTER DEM for Carajás.

Although the requirements for the GCPs number are not specified, a larger number is recommended to improve accuracy for DEM extraction with samples ideally chosen on a variety of locations and ground elevations, at the lowest and highest elevation. On the other hand, ICPs also play a key role in quality control for mapping production. Generally, a balance has to be reached between few ICPs, giving invalid accuracy estimation and an excessive number, providing a safe analysis but with unrealistic cost of acquisition in the field. According to [7] a minimum of 20 well-distributed ICPs is necessary within a map. It is important to mention that the topographic maps in Brazil should be classified according to the National Cartographic Accuracy Standard (PEC). PEC is a statistical indicator (90\% of probability) for planialtimetric accuracy, corresponding to 1.6449 times the RMSE (Root Mean Square Error) $\mathrm{PEC}=1.6449 \times \mathrm{RMSE}$ ). For example, for a 1:100,000 scale A and B Class maps, the altimetric PECs are 25m (RMSE $=16.66 \mathrm{~m})$ and $30 \mathrm{~m}(\mathrm{RMSE}=20 \mathrm{~m})$, respectively. The results in RMSE and LE 90 (elevation linear error with $90 \%$ confidence level) are presented in Table 4.
TABLE 4. Errors for RADARSAT-1, ASTER and SRTM-3

\begin{tabular}{|c|c|c|c|c|}
\hline Product & GCP & ICP & RMSE (m) & LE90 (m) \\
\hline $\begin{array}{c}\text { RADARSAT-1 } \\
\text { (F2/F5) Descend. (*) }\end{array}$ & 19 & 24 & 14.63 & 24.06 \\
\hline $\begin{array}{c}\text { RADARSAT-1 } \\
\text { (F2/F5) Descend. (**) }\end{array}$ & 20 & 14 & 20.11 & 33.08 \\
\hline $\begin{array}{c}\text { RADARSAT-1 } \\
\text { (F5/F2) Ascend. .(*) }\end{array}$ & 13 & 20 & 19.85 & 32.65 \\
\hline $\begin{array}{c}\text { RADARSAT-1 (S5/S7) } \\
\text { Descend. (**) }\end{array}$ & 17 & 20 & 25.36 & 41.71 \\
\hline ASTER (**) & 20 & 20 & 10.55 & 17.35 \\
\hline SRTM-3 (*) & - & 20 & 8.34 & 13.72 \\
\hline SRTM-3 (**) & - & 20 & 6.31 & 10.40 \\
\hline $1: 100,000$ Map (*) & - & 24 & 22.27 & 36.63 \\
\hline $\begin{array}{c}1: 100,000 \text { Map (**) } \\
(* \text { Tapajós, ** Carajás) }\end{array}$ & - & 20 & 17.41 & 28.64 \\
\hline
\end{tabular}

These results allow the following conclusions: (1) for flat relief, the altimetric accuracy of Fine RADARSAT-1 and SRTM-3 DEMs fulfilled the PEC requirements for 1:100,000 A Class Map; (2) for mountainous terrain, the altimetry of ASTER and SRTM-3 also fulfilled the requirements for 1:100,000 A Class, while Fine and Standard RADARSAT-1 were compatible to 1: 100,000 B and 1: 250,000 A Class; (3) SRTM-3 DEMs were more accurate than stereoscopic DEMs or previous 1:100,000 cartographically derived DEMs. Although only two areas with flat and mountainous terrains had been addressed, the findings are in accordance with [5] and favor the use of SRTM-3 as a primary elevation source for topographic mapping. The great advantage of SRTM-3 is the free access data. However, it is important to mention that for cartographic production up-dated planimetric information is also necessary. Thus, a combination of altimetry derived for SRTM and planimetry from SAR (Fine RADARSAT-1, PALSAR) or when possible optical (ASTER, SPOT) can be a good alternative to overcome the critical lack of topographic information (1:100,000 scale) in the Amazon Region.

\section{REFERENCES}

[1] IBGE, "Mapa Índice Digital-Mapeamento Geral do Brasil: Primeira Edição", Brazilian Institute of Geography and Statistics, Rio de Janeiro, Brazil, 2001.

[2] T. Toutin, "Error Tracking of Radargrammetric DEM from RADARSAT Images". IEEE Transactions on Geoscience and Remote Sensing, Vol. 37, No. 5, pp. 2227-2238. 1999.

[3] M. Abrams and S. Hook, "ASTER user handbook", Version 2, Pasadena, Jet Propulsion Laboratory/EROS Data Center, USA, 2001.

[4] T. Toutin, "3D Topographic Mapping with ASTER Stereo Data in Rugged Topography", IEEE Transactions on Geoscience and Remote Sensing, v.40, n.10, p. 2241-2247, 2002.

[5] A. Jarvis, J. Rubiano, A. Nelson, A. Farrow, and M. Muligan, "Practical use of SRTM data in the tropics: comparison with digital elevations models generated from cartographic data", CIAT Working Doc 198, Colombia, 35 p., 2004.

[6] PCI Geomatics Inc., "Geomatica Software Solutions, OESE Reference Manual,: Versions 7.0 and 8.2, Canada, 2000.

[7] D. Merchant, "Spatial Accuracy Specification for Large Scale Topographic Maps", Photogrammetric Engineering and Remote Sensing, Vol. 53, No. 7, pp. 958-961, 1987. 